\title{
Protective Effect of Melatonin Against Mitomycin C-Induced Genotoxic Damage in Peripheral Blood of Rats
}

\author{
S. Ortega-Gutiérrez, ${ }^{1,2}$ M. López-Vicente, ${ }^{1,3}$ F. Lostalé, ${ }^{4}$ L. Fuentes-Broto, ${ }^{1}$ \\ E. Martínez-Ballarín, ${ }^{1}$ and J. J. García ${ }^{1}$ \\ ${ }^{1}$ Department of Pharmacology and Physiology, University of Zaragoza, 50009 Zaragoza, Spain \\ ${ }^{2}$ Departments of Neurology and Medicine, Medical College of Wisconsin, Milwaakee, WI 53226, USA \\ ${ }^{3}$ Department of Family and Community Medicine, Medical College of Wisconsin, Milwaakee, WI 53226, USA \\ ${ }^{4}$ Department of Human Anatomy and Histology, University of Zaragoza, 50009 Zaragoza, Spain
}

Correspondence should be addressed to J. J. García, jjgarcia@unizar.es

Received 22 May 2009; Accepted 5 August 2009

Recommended by Gary S. Stein

\begin{abstract}
Mitomycin C (MMC) generates free radicals when metabolized. We investigated the effect of melatonin against MMC-induced genotoxicity in polychromatic erythrocytes and MMC-induced lipid peroxidation in brain and liver homogenates. Rats $(N=$ 36) were classified into 4 groups: control, melatonin, MMC, and MMC + melatonin. Melatonin and MMC doses of $10 \mathrm{mg} / \mathrm{kg}$ and $2 \mathrm{mg} / \mathrm{kg}$, respectively, were injected intraperitoneally. Peripheral blood samples were collected at $0,24,48,72$, and 96 hours posttreatment and homogenates were obtained at 96 hours posttreatment. The number of micronucleated polychromatic erythrocytes (MN-PCE) per 1000 PCE was used as a genotoxic marker. Malondialdehyde (MDA) plus 4-hydroxyalkenal (4-HDA) levels were used as an index of lipid peroxidation. The MMC group showed a significant increase in MN-PCE at 24, 48, 72, and 96 hours that was significantly reduced with melatonin begin coadministrated. No significant differences were found in lipid peroxidation. Our results indicate that MMC-induced genotoxicity can be reduced by melatonin.
\end{abstract}

Copyright (C) 2009 S. Ortega-Gutiérrez et al. This is an open access article distributed under the Creative Commons Attribution License, which permits unrestricted use, distribution, and reproduction in any medium, provided the original work is properly cited.

\section{Introduction}

Quinones are among the most frequently used chemotherapy drugs in the treatment of cancer [1]. Their antitumor action has been attributed to DNA crosslinking, leading to inhibition of DNA synthesis and monoadduct formation and induction of apoptosis and cell death [2-5]. This DNA damage, as well as drug-associated adverse events such as cardiovascular and skin toxicity, may be related to the formation of reactive oxygen species (ROS) [6,7].

Mitomycin C (MMC) is a quinone-containing antibiotic originally isolated from Streptomyces caespitosus in 1958 [8]. MMC has been used to treat a wide variety of solid tumors. Although current use of MMC is limited, this agent continues to be a key element in several clinical trials due to its intrinsic efficacy against many solid tumors and preferential activity in hypoxic tumoral cells [9]. MMC has a synergistic effect with radiotherapy via its radiosensitizing effects, targeting hypoxic cells in radiation resistant tumors
$[10,11]$. To achieve its alkylating activity, MMC requires a bioreductive transformation to form active species that crosslink DNA [12-14]. Depending on the biotransformation pathway, metabolism of MMC may generate ROS [15]. When ROS interact with cells and exceed endogenous antioxidant systems, there is indiscriminate damage to biological macromolecules such as nucleic acids, proteins, and lipids [16].

Melatonin, N-acetyl-5-methoxytryptamine, is the chief product of the pineal gland in all vertebrates. Retinal light exposure reduces the amount of serotonin metabolized to melatonin via neural pathways connecting the retina to the pineal gland. Thus, pineal production of melatonin increases at night, and the amount of melatonin secreted into the plasma is related to the length of exposure to darkness [17]. Melatonin is involved in the modulation of a variety of endocrine, neural, and immune functions $[17,18]$. Recently, it has been reported to have significant antioxidant activity [19-22]. Its protection against oxidative damage is enhanced 
by its amphiphilic nature, allowing the melatonin molecule to readily access all cell compartments, including the nucleus [23]. Intensive research over the last two decades has shown the beneficial protective effects of melatonin in a multitude of pathological processes. Among them, its anticarcinogenic property has attracted considerable attention $[23,24]$. There is compelling evidence that melatonin may reduce the growth of established tumors [25].

Since cellular harm produced by MMC is thought to be at least partially due to a free radical mechanism, and MMC generates micronuclei-induced genotoxic damage in animal models [26, 27], the aim of this work was to assess the genotoxic effect of MMC. These effects were measured as the number of micronucleated polychromatic erythrocytes (MN-PCE) from the peripheral blood and the ability of MMC to induce lipid peroxidation in cerebral and hepatic homogenates. We also assessed the potential protective action of melatonin against both micronuclei formation and lipid peroxidation processes due to MMC.

\section{Material and Methods}

2.1. Chemicals. Analytical grade agents were obtained from reputable commercial sources. MMC and melatonin were purchased from Sigma-Aldrich (Madrid, Spain). The Bioxytech LPO-586 kit for lipid peroxidation was obtained from Cayman Chemical (Ann Arbor, MI, USA).

2.2. Animal Care and Randomization. Thirty-six SpragueDawley rats weighing 95-100 g were purchased from Harlan Iberica (Barcelona, Spain) and received standard food and water ad libitum. Animal handling and procedures were in strict accordance with the recommendations of the European Economic Community Committee (2007/526/CE) for the care and use of laboratory animals. The experimental protocol was approved by Zaragoza's University Ethical Committee for Animal Research (reference PI24/09).

After acclimation for two weeks with a 12-hour light/dark cycle (lights on at 0700 and off at 1900), the rats were divided to four groups of nine animals in each: control, melatonin, $\mathrm{MMC}$, and MMC + melatonin. MMC was dissolved in saline and injected intraperitoneally in a single dose of $2 \mathrm{mg} / \mathrm{kg}$. Melatonin was dissolved in ethanol and thereafter diluted in saline (final concentration of ethanol: 1\%) and administered intraperitoneally in a dose of $10 \mathrm{mg} / \mathrm{kg}$. Melatonin treatment started 24 hours prior to MMC administration and was given every 8 hours. Control and MMC groups received the dose intraperitoneally and with an equal volume of ethanol/saline solution.

2.3. Tissue Preparation. A $5 \mu \mathrm{L}$ peripheral blood sample was collected from the tail vein of each rat at $0,24,48,72$, and 96 hours after MMC treatment and mounted on two glass slides. Afterwards, the extensions were fixed with methanol for 10 minutes. Following final blood extractions, at 96 hours, the animals were decapitated and the brain and liver were quickly removed, washed in cold saline solution $\left(4^{\circ} \mathrm{C}\right)$, and frozen below $-30^{\circ} \mathrm{C}$ until MDA + 4-HDA assay was performed.
2.4. Peripheral Blood Micronucleus Test. Peripheral blood slides were stained with an acridine orange $(\mathrm{AO})$ fluorescent staining procedure according to Hayashi et al. [28]. A volume of $0.24 \mathrm{mmol} \mathrm{AO}$ in phosphate buffer (PBS) was used as the working solution. The methanol-fixed slides were stained for 3 minutes at room temperature. Each slide was rinsed twice for three minutes. The excess of buffer was removed with paper. The slides were mounted with the same buffer, covered with a $24 \times 60 \mathrm{~mm}$ cover slip, and sealed with paraffin. Using coded slides, the analysis of MN-PCE in each slide was done within 1-2 days by two independent researchers, each analyzing one thousand cells. Utilizing a fluorescent microscope (Zeiss III-RS), the number of MN-PCE per 1000 polychromatic erythrocytes (PCE) was counted and, the ratio of PCE to normochromatic erythrocytes (PCE/NCE) was calculated (from 300 erythrocytes). Subsequently, the code was broken and the counts from each evaluator were averaged. With the $\mathrm{AO}$ fluorescent staining procedure, $\mathrm{PCE}$ containing RNA can be identified by red fluorescence and micronuclei by yellow-green fluorescence. The number of the MN-PCE was expressed per 1000 PCE.

2.5. Measurement of MDA and 4-HDA. MDA + 4-HDA levels were used as an index of oxidative breakdown of lipids in brain and liver tissues [29]. Briefly, samples were homogenized (1:5) (weight/volume) in $20 \mathrm{mmol}$ tris(hydroxymethyl) aminomethane buffer ( $\mathrm{pH}$ 7.4). MDA +4 -HDA were determined using the Bioxytech kit. In the assay, MDA plus 4-HDA reacts with $\mathrm{N}$-methyl-2phenylindole, yielding a stable chromophore with a peak of maximum absorbance at $586 \mathrm{~nm}$. Results were expressed as nmol of MDA + 4-HDA per mg of protein. Protein concentrations in the tissue homogenates were assessed by the Bradford method using bovine serum albumin as a standard [30].

2.6. Statistical Analysis. Results were expressed as means \pm standard errors. Student's unpaired data $t$-test and ANOVA were used for comparison of the means. A $P$ value $<.05$ was considered statistically significant.

\section{Results}

The results of the micronucleus assay obtained in peripheral blood are illustrated in Figure 1. The number of MN-PCE at $24,48,72$, and 96 hours increased significantly in the groups exposed to MMC compared to other groups. No differences were observed in the PCE/NCE ratio (Table 1). The maximal response was observed 48 hours after MMC administration. When compared to MMC alone, melatonin significantly reduced the number of MMC-induced MNPCE in peripheral blood at 24 hours $(6.6 \pm 0.92$ versus $4 \pm 0.67 ; P=.038), 48$ hours $(14.3 \pm 4.77$ versus $5.9 \pm 0.54$; $P=.020), 72$ hours $(7.1 \pm 1.35$ versus $3 \pm 0.41 ; P=.04)$, and 96 hours $(3.5 \pm 0.65$ versus $1 \pm 0.24 ; P=.03)$ while no differences were appreciated between controls $(1.8 \pm 0.63$ versus $1.5 \pm 0.43 ; P=.6)$. 
TABLE 1: The ratio of polychromatic erythrocytes/normochromatic erythrocytes (PCE/NCE) in rat peripheral blood after $0,24,48,72$, and 96 hours in the four treatment groups

\begin{tabular}{lcccrr}
\hline \multirow{2}{*}{ Treatment } & & \multicolumn{3}{c}{ PCE/NCE ratio (mean \pm standard error) } \\
& 0 hour & 24 hours & 48 hours & 72 hours & 96 hours \\
\hline Control & $2.34 \pm 0.05$ & $2.13 \pm 0.06$ & $2.34 \pm 0.02$ & $2.28 \pm 0.08$ & $2.22 \pm 0.03$ \\
aMT & $2.35 \pm 0.07$ & $2.35 \pm 0.07$ & $2.19 \pm 0.07$ & $2.23 \pm 0.03$ & $2.30 \pm 0.03$ \\
MMC & $2.22 \pm 0.06$ & $2.13 \pm 0.03$ & $2.11 \pm 0.10$ & $2.20 \pm 0.06$ & $2.10 \pm 0.09$ \\
MMC + aMT & $1.95 \pm 0.04$ & $2.09 \pm 0.07$ & $2.05 \pm 0.02$ & $2.10 \pm 0.07$ & $2.16 \pm 0.05$ \\
\hline
\end{tabular}

MMC: mitomycin C; aMT: melatonin

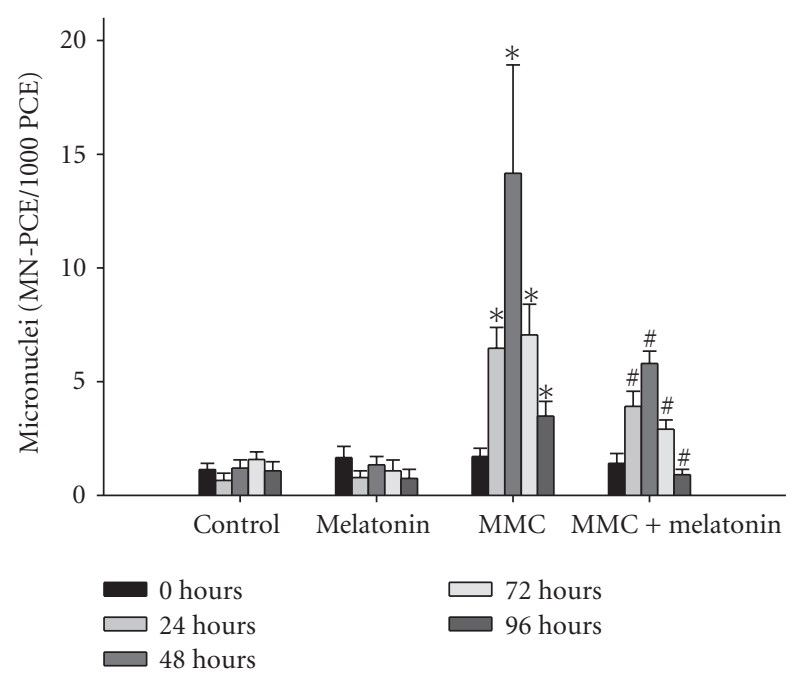

Figure 1: Micronucleated polychromatic erythrocytes (MN-PCE) per 1000 polychromatic erythrocytes (PCE) in peripheral blood at $0,24,48,72$, and 96 hours in four rat groups $(n=9)$ : control, mitomycin (MMC), melatonin, and $\mathrm{MMC}+$ melatonin. Data are expressed as means \pm standard error. $P<0.05$ versus control $(*)$ or versus MMC (\#).

No statistically significant differences of MDA + 4-HDA were found in brain or liver when the averages of each group were compared (Figure 2). These results indicate the absence of lipid peroxidation due to MMC in these organs under our experimental conditions.

\section{Discussion}

Our results show that in vivo exposure to MMC induces genotoxicity as indicated by increases in the number of $\mathrm{MN}$ PCE at 24, 48, 72, and 96 hours posttreatment. This is in accordance with previous studies demonstrating MMCinduced micronuclei $[26,31,32]$. Several in vitro and in vivo studies have shown that different MMC metabolic pathways result in ROS generation [33-35], and that some MMC metabolites may form cross-links to adjacent guanines in DNA [36-39]. Quinones, including MMC, streptonigrin, and adriamycin, produce ROS as result of one- or twoelectron reduction metabolism [40-42]: firstly, they or their one-electron reduction product, semiquinones $\left(\mathrm{SQ} \bullet^{-}\right)$, may react with glutathione and protein-SH groups through a

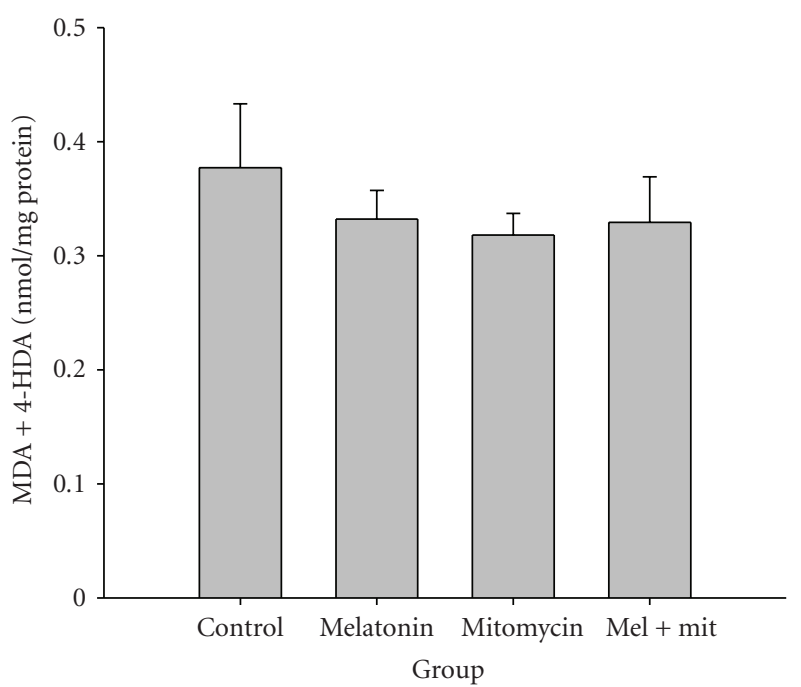

(a)

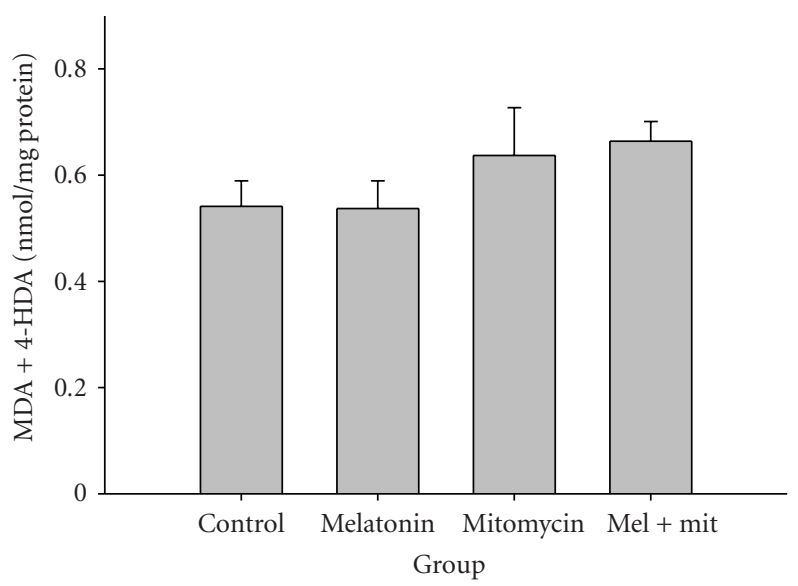

(b)

Figure 2: Malondialdehyde (MDA) plus 4-hydroxyalkenals (4HDA) concentrations in brain (a) and liver (b) homogenates from rats in the presence or absence of treatment with mitomycin $\mathrm{C}$ $(\mathrm{MMC})$ or melatonin. Values are mean \pm standard error.

nonenzymatic and/or glutathione transferase reaction; secondly, SQ $\bullet^{-}$may generate superoxide anion radicals depending on the equilibrium potential and the $\mathrm{pH}[43,44]$; thirdly, $\mathrm{SQ} \bullet^{-}$and superoxide anion radicals can reduce transitionmetal ions, such as iron and copper, and promote the hydroxyl radical generation via the Fenton reaction $[33,45]$. 
On the other hand, our results show that, after 96 hours of MMC treatment, this quinone does not induce lipid peroxidation in homogenates of brain and liver, as indicated by its inability to modify significantly MDA + 4-HDA concentrations. However, free radicals involve the micronuclei formation [46] and we have demonstrated that the antioxidant indoleamine melatonin had a protective effect against MMC genotoxicity in rat red blood cell precursors in vivo, suggesting that MMC-induced PCE$\mathrm{MN}$ elevation may be mediated by free radical generation. Possible explanations for the lack of lipid peroxidation induced by MMC could be that the ROS generated as a consequence of MMC metabolism is insufficiently powerful to generate or propagate lipid peroxidation or that, after 96 hours, MDA + 4-HDA concentrations were reduced by renal clearance.

Recent interest has focused on the use of molecules that may partly reduce the side effects of MMC. Several free radical scavenger agents, such as amifostine and nitroxide, prevent the cytotoxic damage mediated by MMC in different organs [47-49]. In fact, the United States Food and Drug Administration (FDA) recently approved amifostine for use as a cytoprotectant in combination with cyclophosphamide and cisplatin for the treatment of advanced ovarian cancer and nonsmall cell lung cancer [50]. Lipoic acid, another antioxidant, has also demonstrated an in vivo dose-dependent protective effect against cyclophosphamideinduced clastogenicity in the peripheral blood and bone marrow of rats [51]. Herein, we have extended the evidence of melatonin as a cell protector, since cotreatment of MMC and melatonin significantly reduced the number of $\mathrm{MN}$ PCE. This is in accordance with the results of previous studies showing a significant reduction in micronuclei induction by different genotoxic molecules in peripheral blood and bone marrow samples [52, 53]. Moreover, melatonin is also capable of preventing DNA damage induced by not only mutagens but also different alkylating agents such as 7,12-dimethybenz $(\alpha)$ anthracene, cyclophosphamide, and benzo $(\alpha)$ pyrene [54].

Melatonin protection against DNA damage and oncogenesis is thought to be due in part to its antioxidant properties. Melatonin, an indoleamine, directly scavenges hydroxyl radicals, singlet oxygen, and peroxynitrites [19, 55-57], increases the concentration of endogenous glutathione, and stimulates the antioxidative enzymes superoxide dismutase and glutathione peroxidase [58]. Moreover, melatonin has been shown to prevent iron-induced lipid peroxidation [59]. Thus melatonin may also prevent carcinogenesis [60].

Additionally, once oncogenesis has occurred; melatonin seems to control cancer growth by means other than its antioxidant activity. Melatonin might inhibit the uptake and metabolism of fatty acid signaling molecules that promote the production of tumoral growth factors [61], reduce telomerase activity by shortening telomer length [62], and modulate expression of tumor suppressor genes such as TP53 [63]. More recent studies report that melatonin significantly suppresses endothelin-1 converting enzyme activity [64]. Endothelin-1 is a potent vasoconstrictor peptide that is involved in angiogenesis and cancer growth. This peptide is usually elevated in the plasma of patient with various solid tumors and acts to protect cancer cells from apoptosis and promote endothelial and smooth muscle proliferation [65]. Finally, the antiestrogenic activity of melatonin also seems to play a role in its ability to decrease proliferation in some hormone-responsive tumors. Physiological and pharmacological concentrations of melatonin exhibited a growth inhibitory effect on MCF-7 human breast cancer cell lines $[66,67]$. In fact, this effect was particularly manifested in cancer cell lines possessing the estrogen receptor $\alpha(\mathrm{ER} \alpha)$; this effect seems to be mediated by both membrane (MT1) and nuclear $(\mathrm{RZR} \alpha)$ melatonin receptors [68].

\section{Conclusion}

In conclusion, the data reported herein provide evidence that melatonin reduces genotoxicity due to MMC, presumably due to its antioxidant effects. Based on our observations and previous results showing that oxidative stress participates in carcinogenesis and the role of melatonin as an anticarcinogenic agent with broad bioavailability and lack of side effects [23], it seems reasonable to propose that cotreatment with melatonin may be beneficial when used in combination with MMC for the treatment of some cancers.

\section{Acknowledgments}

This work was supported by the Gobierno de Aragón (Aging and Oxidative Stress Physiology, Grant no. B40) and by F.I.S. from Instituto de Salud Carlos III (Grant no. RD06/0013/1017).

\section{References}

[1] C. Asche, "Antitumour quinones," Mini-Reviews in Medicinal Chemistry, vol. 5, no. 5, pp. 449-467, 2005.

[2] M. Tomasz and Y. Palom, "The mitomycin bioreductive antitumor agents: cross-linking and alkylation of DNA as the molecular basis of their activity," Pharmacology and Therapeutics, vol. 76, no. 1-3, pp. 73-87, 1997.

[3] Y. Palom, G. Suresh Kumar, L.-Q. Tang, et al., "Relative toxicities of DNA cross-links and monoadducts: new insights from studies of decarbamoyl mitomycin C and mitomycin C," Chemical Research in Toxicology, vol. 15, no. 11, pp. 13981406, 2002.

[4] M. M. Paz, G. S. Kumar, M. Glover, M. J. Waring, and M. Tomasz, "Mitomycin dimers: polyfunctional cross-linkers of DNA," Journal of Medicinal Chemistry, vol. 47, no. 12, pp. 3308-3319, 2004.

[5] Y.-J. Lee, S.-J. Park, S. L. M. Ciccone, C.-R. Kim, and S.-H. Lee, "An in vivo analysis of MMC-induced DNA damage and its repair," Carcinogenesis, vol. 27, no. 3, pp. 446-453, 2006.

[6] G. Powis, "Free radical formation by antitumor quinines," Free Radicals in Biology and Medicine, vol. 6, pp. 63-101, 1989.

[7] P. L. Gutiérrez, "The metabolism of quinine-containing alkylating agents: free radical production and measurement," Frontiers in Biosciences, vol. 5, pp. 629-638, 2000.

[8] S. Wakaki, H. Marumo, K. Tomiaka, et al., "Isolation of new fractions of antitumor mitomycin," Antibiotics \& Chemotherary, vol. 8, pp. 228-240, 1958. 
[9] P. Workman and I. J. Stratford, "The experimental development of bioreductive drugs and their role in cancer therapy," Cancer and Metastasis Reviews, vol. 12, no. 2, pp. 73-82, 1993.

[10] A. C. Sartorelli, W. F. Hodnick, M. F. Belcourt, et al., "Mitomycin C: a prototype bioreductive agent," Oncology Research, vol. 6, no. 10-11, pp. 501-508, 1994.

[11] K. Pors and L. H. Patterson, "DNA mismatch repair deficiency, resistance to cancer chemotherapy and the development of hypersensitive agents," Current Topics in Medicinal Chemistry, vol. 5, no. 12, pp. 1133-1149, 2005.

[12] Y. Na, V.-S. Li, Y. Nakanishi, K. F. Bastow, and H. Kohn, "Synthesis, DNA cross-linking activity, and cytotoxicity of dimeric mitomycins," Journal of Medicinal Chemistry, vol. 44, no. 21, pp. 3453-3462, 2001.

[13] S.-L. Wang, J.-F. Han, X.-Y. He, X.-R. Wang, and J.-Y. Hong, "Genetic variation of human cytochrome P450 reductase as a potential biomarker for mitomycin C-induced cytotoxicity," Drug Metabolism and Disposition, vol. 35, no. 1, pp. 176-179, 2007.

[14] R. T. Dorr, "New findings in the pharmacokinetic, metabolic, and drug-resistance aspects of mitomycin C," Seminars in Oncology, vol. 15, no. 3, supplement 4, pp. 32-41, 1988.

[15] D. L. Gustafson and C. A. Pritsos, "Oxygen radical generation and alkylating ability of mitomycin $\mathrm{C}$ bioactivated by xanthine dehydrogenase," Proceedings of the Western Pharmacology Society, vol. 35, pp. 147-151, 1992.

[16] E. Offord, G. van Poppel, and R. Tyrrell, "Markers of oxidative damage and antioxidant protection: current status and relevance to disease," Free Radical Research, vol. 33, supplement, pp. S5-S19, 2000.

[17] R. J. Reiter, "Pineal melatonin: cell biology of its synthesis and of its physiological interactions," Endocrine Reviews, vol. 12, no. 2, pp. 151-180, 1991.

[18] A. Carrillo-Vico, R. J. Reiter, P. J. Lardone, et al., "The modulatory role of melatonin on immune responsiveness," Current Opinion in Investigational Drugs, vol. 7, no. 5, pp. 423431,2006

[19] D. X. Tan, L. D. Chen, B. Poeggeler, et al., "Melatonin: a potent, endogenous hydroxyl radical scavenger," Endocrine Journal, vol. 1, pp. 57-60, 1993.

[20] S. Ortega-Gutiérrez, J. J. García, E. Martínez-Ballarín, et al., "Melatonin improves deferoxamine antioxidant activity in protecting against lipid peroxidation caused by hydrogen peroxide in rat brain homogenates," Neuroscience Letters, vol. 323, no. 1, pp. 55-59, 2001.

[21] M.-J. Jou, T.-I. Peng, P.-Z. Yu, et al., "Melatonin protects against common deletion of mitochondrial DNA-augmented mitochondrial oxidative stress and apoptosis," Journal of Pineal Research, vol. 43, no. 4, pp. 389-403, 2007.

[22] E. Gitto, S. Pellegrino, P. Gitto, I. Barberi, and R. J. Reiter, "Oxidative stress of the newborn in the pre- and postnatal period and the clinical utility of melatonin," Journal of Pineal Research, vol. 46, no. 2, pp. 128-139, 2009.

[23] T. C. Erren and R. J. Reiter, "A generalized theory of carcinogenesis due to chronodisruption," Neuroendocrinology Letters, vol. 29, no. 6, pp. 815-821, 2008.

[24] M. Karbownik, A. Lewinski, and R. J. Reiter, "Anticarcinogenic actions of melatonin which involve antioxidative processes: comparison with other antioxidants," International Journal of Biochemistry and Cell Biology, vol. 33, no. 8, pp. 735-753, 2001.

[25] Vijayalaxmi, C. R. Thomas Jr., R. J. Reiter, and T. S. Herman, "Melatonin: from basic research to cancer treatment clinics," Journal of Clinical Oncology, vol. 20, no. 10, pp. 2575-2601, 2002.
[26] M. Hayashi, Y. Kodama, T. Awogi, T. Suzuki, A. O. Asita, and T. Sofuni, "The micronucleus assay using peripheral blood reticulocytes from mitomycin C- and cyclophosphamidetreated rats," Mutation Research, vol. 278, no. 2-3, pp. 209-213, 1992.

[27] C. K. Grisolia, "A comparison between mouse and fish micronucleus test using cyclophosphamide, mitomycin $\mathrm{C}$ and various pesticides," Mutation Research, vol. 518, no. 2, pp. 145$150,2002$.

[28] M. Hayashi, T. Sofuni, and M. Ishidate Jr., "An application of acridine orange fluorescent staining to the micronuclear test," Mutation Research, vol. 120, no. 4, pp. 241-247, 1983.

[29] D. R. Janero, "Malondialdehyde and thiobarbituric acidreactivity as diagnostic indices of lipid peroxidation and peroxidative tissue injury," Free Radical Biology and Medicine, vol. 9, no. 6, pp. 515-540, 1990.

[30] M. M. Bradford, "A rapid and sensitive method for the quantification of microgram quantities of protein utilizing the principle of protein-dying binding," Analytical Biochemistry, vol. 72, pp. 248-254, 1976.

[31] M. Hayashi, T. Morita, Y. Kodama, T. Sofuni, and M. Ishidate Jr., "The micronucleus assay with mouse peripheral blood reticulocytes using acridine orange-coated slides," Mutation Research, vol. 245, no. 4, pp. 245-249, 1990.

[32] P. Morales-Ramírez, Y. Vallarino-Kelly, V. L. Cruz-Vallejo, et al., "In vivo kinetics of micronuclei induction by dysfunctional alkylating antineoplastics," Mutagenesis, vol. 19, pp. 207-213, 2004.

[33] G. R. Fisher, L. H. Patterson, and P. L. Gutiérrez, "A comparison of free radical formation by quinone antitumor agents in MCF-7 cells and the role of NAD(P)H (quinone-acceptor) oxidoreductase (DT-diaphorase)," Chemico-Biological Interactions, vol. 88, pp. 137-153, 1993.

[34] B. K. Sinha and E. G. Mimnaugh, "Free radicals and anticancer drug resistance: oxygen free radicals in the mechanisms of drug cytotoxicity and resistance by certain tumors," Free Radical Biology and Medicine, vol. 8, no. 6, pp. 567-581, 1990.

[35] K. Sato, T. Akaike, Y. Kojima, M. Ando, M. Nagao, and H. Maeda, "Evidence of direct generation of oxygen free radicals from heterocyclic amines by NADPH/Cytochrome P450 reductase in vitro," Japanese Journal of Cancer Research, vol. 83, no. 11, pp. 1204-1209, 1992.

[36] M. M. Paz, A. Das, and M. Tomasz, "Mitomycin C linked to DNA minor groove binding agents: synthesis, reductive activation, DNA binding and cross-linking properties and in vitro antitumor activity," Bioorganic and Medicinal Chemistry, vol. 7, no. 12, pp. 2713-2726, 1999.

[37] J. Cummings, V. J. Spanswick, and J. F. Smyth, "Re-evaluation of the molecular pharmacology of mitomycin C," European Journal of Cancer, vol. 31, no. 12, pp. 1928-1933, 1995.

[38] J. Cummings, V. J. Spanswick, M. Tomasz, and J. F. Smyth, "Enzymology of mitomycin C metabolic activation in tumour tissue," Biochemical Pharmacology, vol. 56, no. 4, pp. 405-414, 1998.

[39] P. Wang, Y. Song, L. Zhang, et al., "Quinone methane derivates: important intermediates to DNA alkylating and DNA cross-linking actions," Current Medicinal Chemistry, vol. 12, pp. 2893-2913, 2005.

[40] P. L. Gutiérrez, "The role of NAD(P)H oxidoreductase (DTDiaphorase) in the bioactivation of quinone-containing antitumor agents: a review," Free Radical Biology and Medicine, vol. 29, no. 3-4, pp. 263-275, 2000. 
[41] A. D. Bolzan and M. S. Bianchi, "Genotoxicity of streptonigrin: a review," Mutation Research, vol. 488, no. 1, pp. 25-37, 2001.

[42] W. G. De Graff, L. S. Myers Jr., J. B. Mitchell, and S. M. Hahn, "Protection against Adriamycin cytotoxicity and inhibition of DNA topoisomerase II activity by 3,4-dihydroxybenzoic acid," International Journal of Oncology, vol. 23, no. 1, pp. 159-163, 2003.

[43] T. J. Monks, R. P. Hanzlik, G. M. Cohen, D. Ross, and D. G. Graham, "Quinone chemistry and toxicity," Toxicology and Applied Pharmacology, vol. 112, no. 1, pp. 2-16, 1992.

[44] Y. Li, P. Kuppusamy, J. L. Zweier, and M. A. Trush, "Role of $\mathrm{Cu} / \mathrm{Zn}$-superoxide dismutase in xenobiotic activation. I. Chemical reactions involved in the $\mathrm{Cu} / \mathrm{Zn}$-superoxide dismutase-accelerated oxidation of the benzene metabolite 1,4-hydroquinone," Molecular Pharmacology, vol. 49, no. 3, pp. 404-411, 1996.

[45] P. Kovacic and J. A. Osuna Jr., "Mechanisms of anti-cancer agents: emphasis on oxidative stress and electron transfer," Current Pharmaceutical Design, vol. 6, no. 3, pp. 277-309, 2000.

[46] Vijayalaxmi, M. L. Meltz, R. J. Reiter, and T. S. Herman, "Melatonin and protection from genetic damage in blood and bone marrow: whole-body irradiation studies in mice," Journal of Pineal Research, vol. 27, no. 4, pp. 221-225, 1999.

[47] M. C. Krishna, W. DeGraff, S. Tamura, et al., "Mechanisms of hypoxic and aerobic cytotoxicity of mitomycin $\mathrm{C}$ in Chinese hamster V79 cells," Cancer Research, vol. 51, no. 24, pp. 66226628, 1991.

[48] S. M. Hahn, F. J. Sullivan, A. M. DeLuca, et al., "Protection of mitomycin $\mathrm{C}$ induced skin extravation with the nitroxide, 3carbamoyl-proxyl (3-CP)," International Journal of Oncology, vol. 10, pp. 119-123, 1997.

[49] V. Santini, "Amifostine: chemotherapeutic and radiotherapeutic protective effects," Expert Opinion on Pharmacotherapy, vol. 2, no. 3, pp. 479-489, 2001.

[50] C. Sriswasdi, S. Jootar, and F. J. Giles, "Amifostine and hematologic effects," Journal of the Medical Association of Thailand, vol. 83, no. 4, pp. 374-382, 2000.

[51] E. Selvakumar, C. Prahalathan, P. T. Sudharsan, and P. Varalakshmi, "Protective effect of lipoic acid on micronuclei induction by cyclophosphamide," Archives of Toxicology, vol. 80, no. 2, pp. 115-119, 2006.

[52] G. A. Elmegeed, W. K. B. Khalil, A. A. Raouf, and M. M. Abdelhalim, "Synthesis and in vivo anti-mutagenic activity of novel melatonin derivatives," European Journal of Medicinal Chemistry, vol. 43, no. 4, pp. 763-770, 2008.

[53] G. G. Ortiz, R. J. Reiter, G. Zúñiga, et al., "Genotoxicity of paraquat: micronuclei induced in bone marrow and peripheral blood are inhibited by melatonin," Mutation Research, vol. 464, no. 2, pp. 239-245, 2000.

[54] S. A. Musatov, V. N. Anisimov, V. André, et al., "Modulatory effects of melatonin on genotoxic response of reference mutagens in the Ames test and the comet assay," Mutation Research, vol. 417, no. 2-3, pp. 75-84, 1998.

[55] C. M. Cagnoli, C. Atabay, E. Kharlamova, and H. Manev, "Melatonin protects neurons from singlet oxygen-induced apoptosis," Journal of Pineal Research, vol. 18, no. 4, pp. 222226, 1995.

[56] D. X. Tan, R. J. Reiter, L. C. Manchester, et al., "Chemical and physical properties and potential mechanisms: melatonin as a broad spectrum antioxidant and free radical scavenger," Current Topics in Medicinal Chemistry, vol. 2, no. 2, pp. 181197, 2002.
[57] E. Gilad, S. Cuzzocrea, B. Zingarelli, et al., "Melatonin is a scavenger of peroxinitrite," Life Sciences, vol. 60, pp. PL169PL174, 1997.

[58] I. Antolín, C. Rodríguez, R. M. Sáinz, et al., "Neurohormone melatonin prevents cell damage: effect on gene expression for antioxidant enzymes," FASEB Journal, vol. 10, no. 8, pp. 882890, 1996.

[59] S. Ortega-Gutiérrez, L. Fuentes-Broto, J. J. García, et al., "Melatonin reduces protein and lipid oxidative damage induced by homocysteine in rat brain homogenates," Journal of Cellular Biochemistry, vol. 102, no. 3, pp. 729-735, 2007.

[60] P. C. Burcham, "Genotoxic lipid peroxidation products: their DNA damaging properties and role in formation of endogenous DNA adducts," Mutagenesis, vol. 13, no. 3, pp. 287-305, 1998.

[61] D. E. Blask, R. T. Dauchy, L. A. Sauer, and J. A. Krause, "Melatonin uptake and growth prevention in rat hepatoma $7288 \mathrm{CTC}$ in response to dietary melatonin: melatonin receptor-mediated inhibition of tumor linoleic acid metabolism to the growth signaling molecule 13hydroxyoctadecadienoic acid and the potential role of phytomelatonin," Carcinogenesis, vol. 25, no. 6, pp. 951-960, 2004.

[62] M. M. León-Blanco, J. M. Guerrero, R. J. Reiter, J. R. Calvo, and D. Pozo, "Melatonin inhibits telomerase activity in the MCF7 tumor cell line both in vivo and in vitro," Journal of Pineal Research, vol. 35, no. 3, pp. 204-211, 2003.

[63] E. Mazzon, E. Esposito, C. Crisafulli, et al., "Melatonin modulates signal transduction pathways and apoptosis in experimental colitis," Journal of Pineal Research, vol. 41, no. 4, pp. 363-373, 2006.

[64] E. Kilic, Ü. Kilic, R. J. Reiter, C. L. Bassetti, and D. M. Hermann, "Prophylactic use of melatonin protects against focal cerebral ischemia in mice: role of endothelin converting enzyme-1," Journal of Pineal Research, vol. 37, no. 4, pp. 247251, 2004.

[65] K. Grant, M. Loizidou, and I. Taylor, "Endothelin-I: a multifunctional molecule in cancer," British Journal of Cancer, vol. 88, no. 2, pp. 163-166, 2003.

[66] P. T. Ram, L. Yuan, J. Dai, et al., "Differential responsiveness of MCF-7 human breast cancer cell line stocks to the pineal hormone, melatonin," Journal of Pineal Research, vol. 28, no. 4, pp. 210-218, 2000.

[67] Y. Kanishi, Y. Kobayashi, S. Noda, B. Ishizuka, and K. Saito, "Differential growth inhibitory effect of melatonin on two endometrial cancer cell lines," Journal of Pineal Research, vol. 28, no. 4, pp. 227-233, 2000.

[68] R. Girgert, C. Bartsch, S. M. Hill, R. Kreienberg, and V. Hanf, "Tracking the elusive antiestrogenic effect of melatonin: a new methodological approach," Neuroendocrinology Letters, vol. 24, no. 6, pp. 440-444, 2003. 

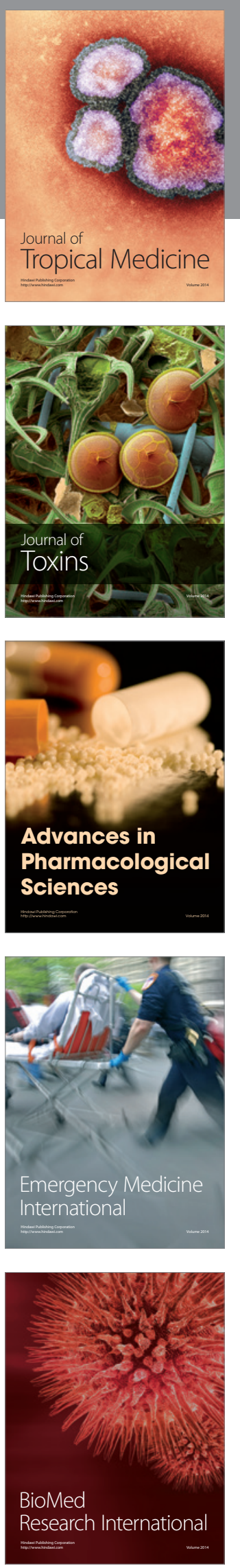
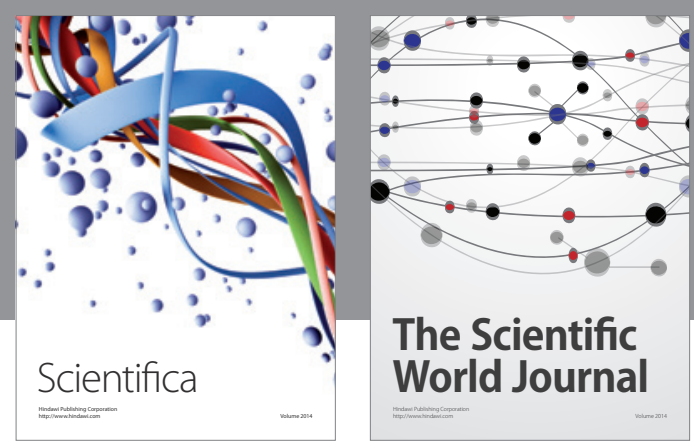

The Scientific World Journal
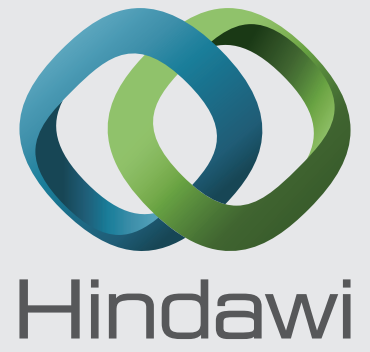

Submit your manuscripts at

http://www.hindawi.com
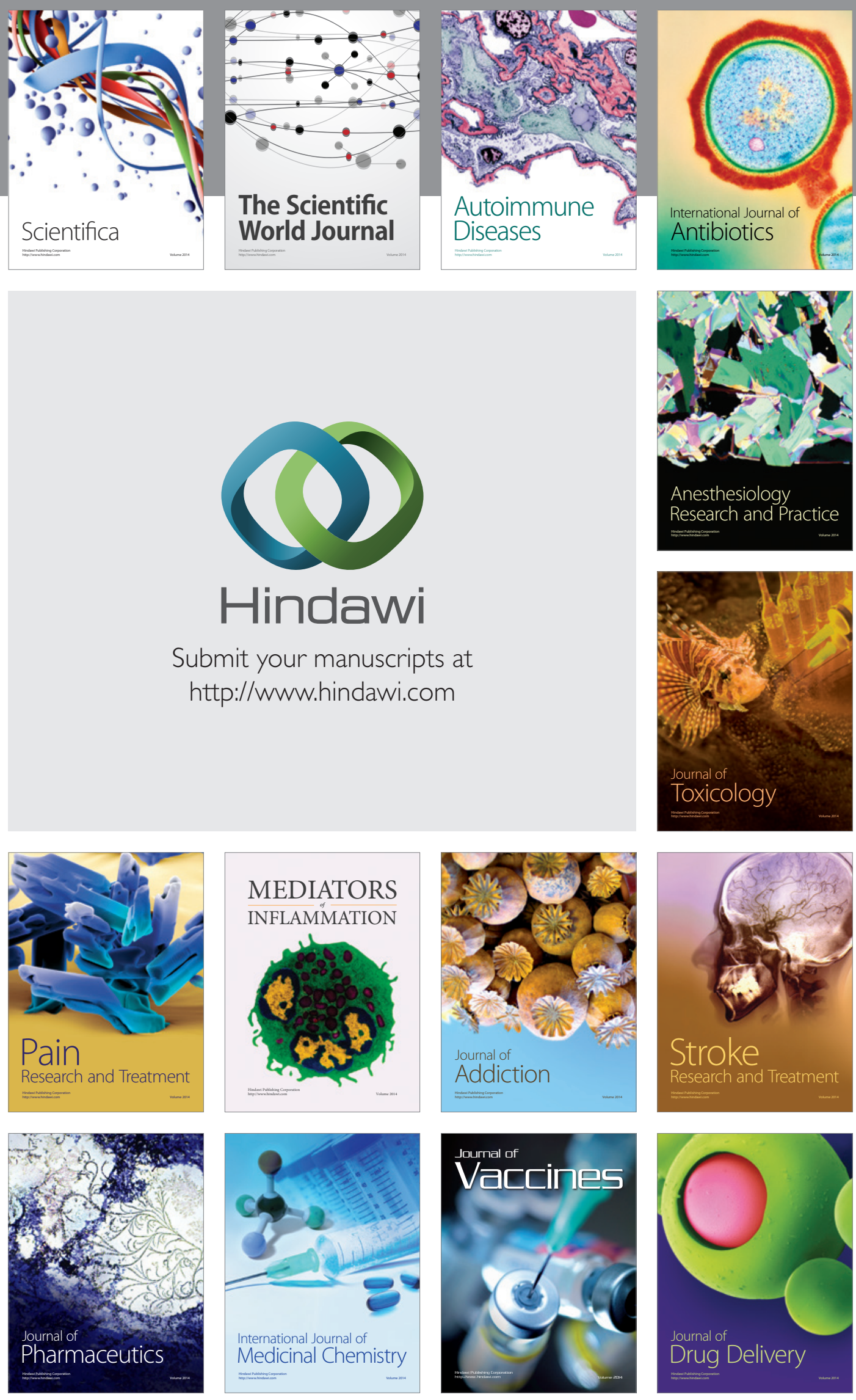